\title{
The impact of biological frailty syndrome on quality of life of nursing home residents
}

Ma Dolores Serrano, PhD, RN

dolores.serrano@uclm.es

Margarita Garrido, PhD, $\mathrm{RN}^{*}$

margarita.garrido@uclm.es

Rosa Ma

rosa.fuentes@uclm.es

Ma José Simón, RN

mjose.simon@uclm.es

Ma José Díaz, RN

Department of Nursing, Institute for Research in Neurological Disabilities - IDINE, University of Castilla la Mancha, Cuenca, Spain

*Corresponding author at: Department of Nursing, University of Castilla Mancha, Edificio “Melchor Cano” C/Santa Teresa Jornet s/n, 16071 Cuenca, Spain

\subsection{Introduction}

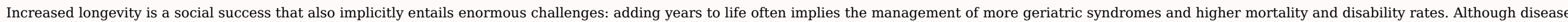
and disability are not inevitable consequences of human ageing, the risk of being affected by them considerably increases with age (Baltes \& Smith, 2003)

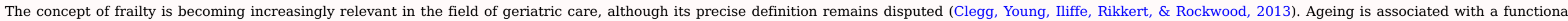

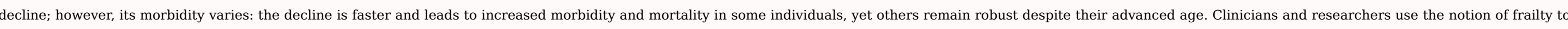

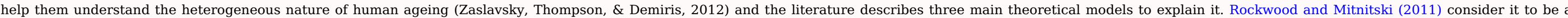

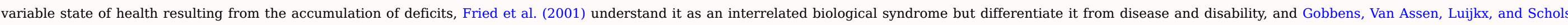
(2012) take a comprehensive view of frailty.

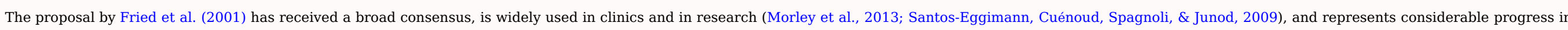

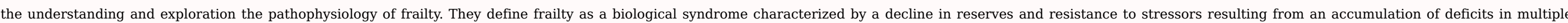

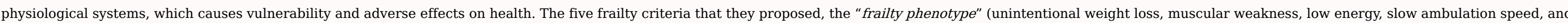

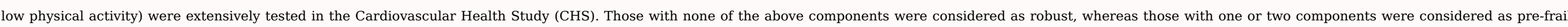

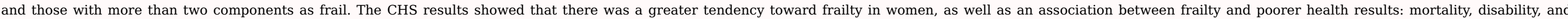

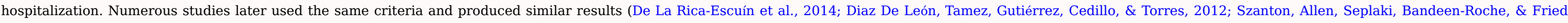
2009).

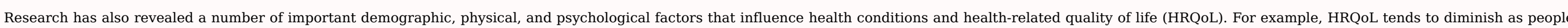

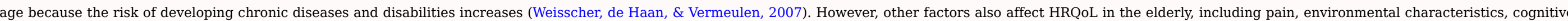

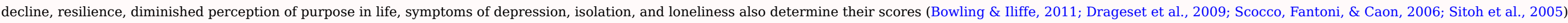

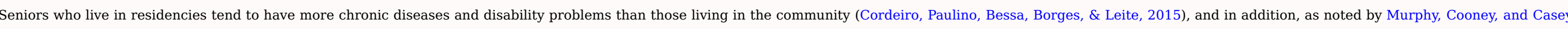

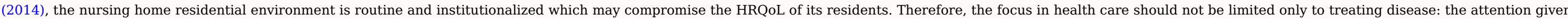

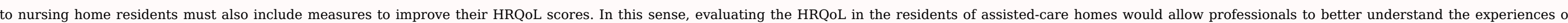




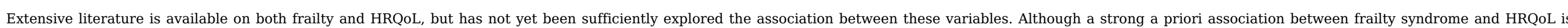

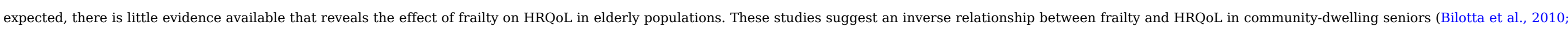

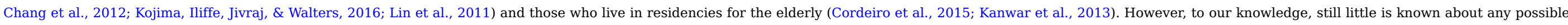

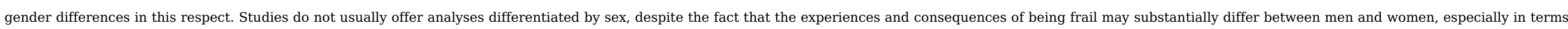
of its impact on HRQoL. Moreover, because frailty is a biological syndrome it is not clear how it impacts the mental dimension of the HRQoL.

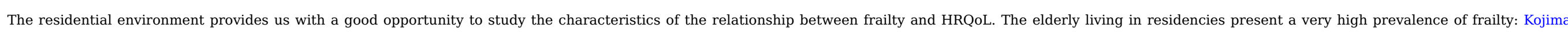

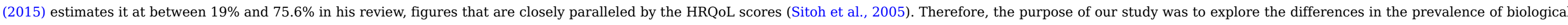

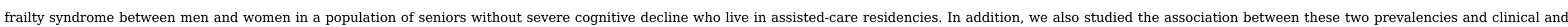
psychosocial variables, as well as their impact on the physical and mental dimensions of HRQoL.

\subsection{Methods \\ 2.1.2.1 Design}

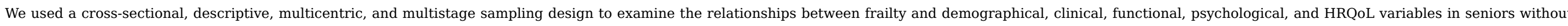

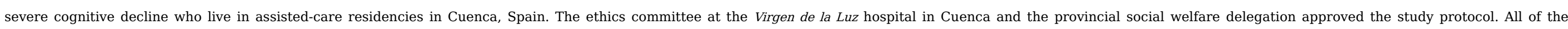
participants gave their informed consent and the investigators promise to maintain the anonymity and confidentiality of the data.

\subsubsection{Participants and setting}

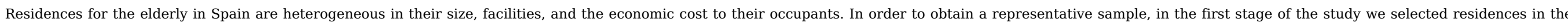

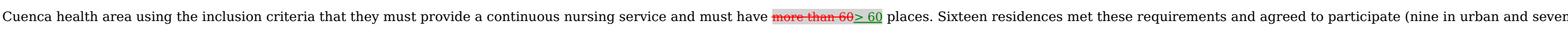
in rural environments)

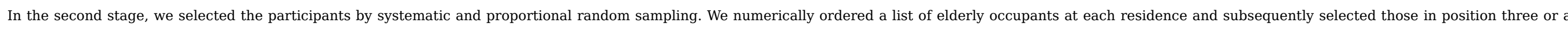

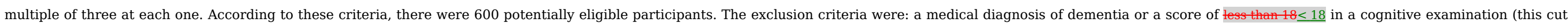

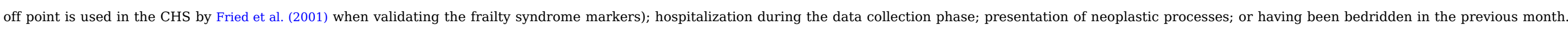

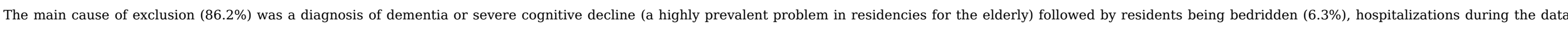
collection phase (4.7\%), or those who did not wish to participate in the study (2.8\%). Two-hundred-and eighty-one elderly residents finally met the inclusion criteria and gave their informed consent.

\subsubsection{Measurements}

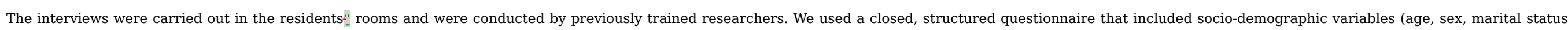
and education level), and used the following measurement instruments:

\subsection{Frailty measures}

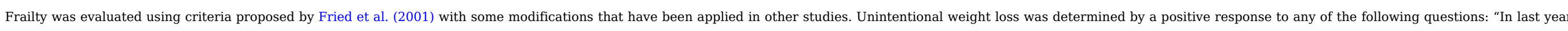

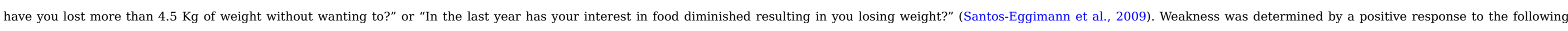

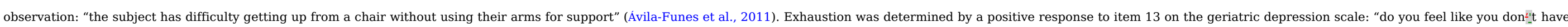

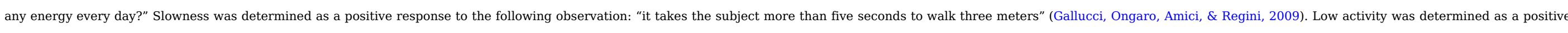

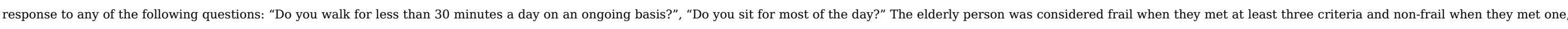




\subsection{Health-related quality of life}

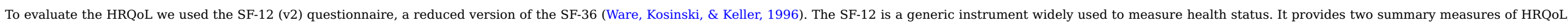
the physical component score (PCS) and the mental component score (MCS) which range from 0 to 100, with higher scores indicating a better HRQoL score.

\subsection{Co-morbidity}

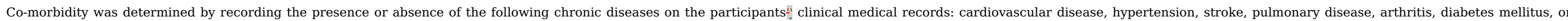
mental disorders. Infectious diseases and acute problems were excluded. Comorbidity was calculated using the sum of the evaluated variables and ranged between 0 -and 7 .

\subsection{Physical function}

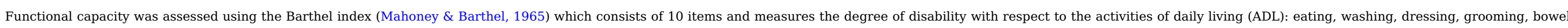
control, urination control, toilet use, movement between places, ambulation, and stair climbing. It ranges from 0- to 100 , and the higher the score, the greater the level of independence.

\subsection{Cognitive status}

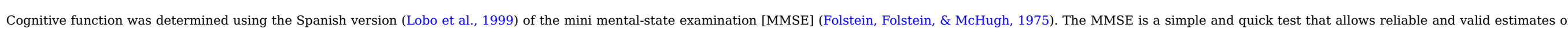

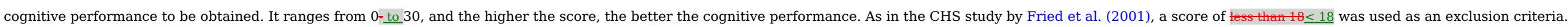

\subsection{Depression}

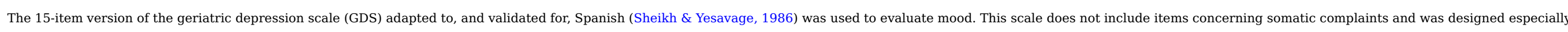
to evaluate depression in seniors; higher scores indicate the presence of more symptoms of depression.

\subsubsection{Data Aanalysis}

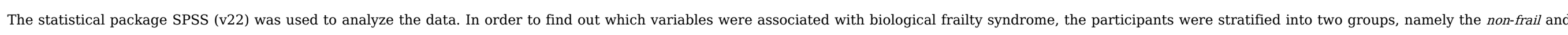
frail groups according to the criteria set out by Fried et al. (2001).

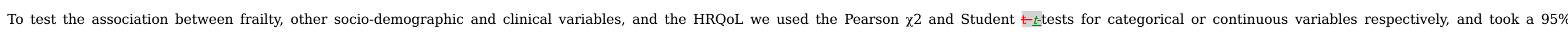
confidence interval as the cut-off for significance ( $p<-\underline{0} .05)$.

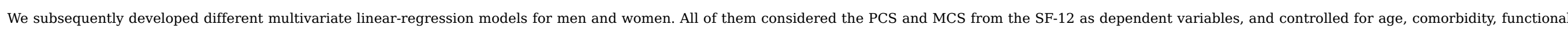
status, frailty, and symptoms of depression.

\section{3. $\underline{3}$ Results}

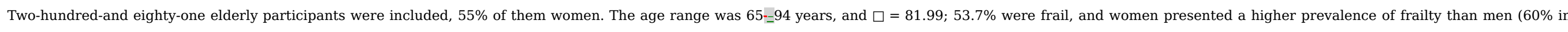

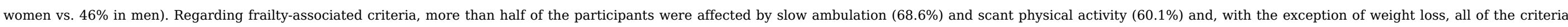
were more frequent in women, although the difference was only significant for muscular weakness (Table 1).

Table 1 Prevalence of Frailty and percentage of clinical criteria in men and women. alt-text: Table 1 


\begin{tabular}{|c|c|c|c|c|c|c|}
\hline Nonfrail & $130-46.1$ & 68 & 54.0 & 62 & 40.0 & 0.020 \\
\hline Frail ( $\geq 3$ criteria) & $151-53.7$ & 58 & 46.0 & 93 & 60.0 & \\
\hline \multicolumn{7}{|l|}{ Frailty criteria } \\
\hline Slowness & 193-68.6 & 80 & 63.5 & 113 & 72.0 & 0.091 \\
\hline Low activity & 169-60.1 & 69 & 54.8 & 100 & 64.5 & 0.062 \\
\hline Weakness & $130-46.2$ & 48 & 38.0 & -82 & 52.9 & 0.013 \\
\hline Exhaustion & $114-40.5$ & 46 & 36.0 & -68 & 43.8 & 0.211 \\
\hline Unintentional weight loss & $-47-\_16.7$ & 25 & 19.8 & -22 & 14.2 & 0.207 \\
\hline
\end{tabular}

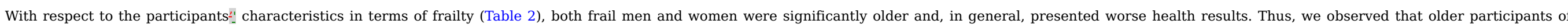

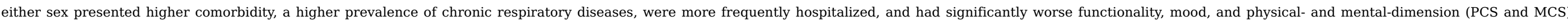

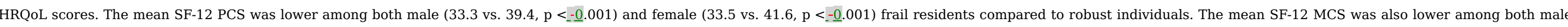

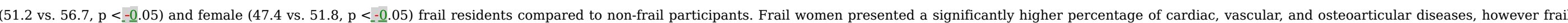
men were hospitalized more often than frail women ( $56.9 \%$ vs. $39.8 \%)$.

Table 2 Characteristics of participants by frailty status.

alt-text: Table 2

\begin{tabular}{|c|c|c|c|c|}
\hline & \multicolumn{2}{|c|}{ Men } & \multicolumn{2}{|c|}{ Women } \\
\hline & Nonfrail $(n=68)$ & Frail $(\mathrm{n}=58)$ & Nonfrail $(\mathrm{n}=62)$ & Frail $(\mathrm{n}=93)$ \\
\hline Age mean (SD) & $79.8(7.8)$ & $82.8(6.7) *$ & $80.7(8.4)$ & $83.8(6.7) *$ \\
\hline Co-morbidities mean (SD) & $1.4(0.9)$ & $1.9(1.2) *$ & $1.3(1.2)$ & $2.4(1.2) * *$ \\
\hline Cardiovascular disease $\mathrm{n} \%$ & 1319.1 & 1525.8 & 69.7 & $2122.5 *$ \\
\hline Hypertension n \% & 3247.1 & 2543.1 & 2743.5 & $5862.4 *$ \\
\hline Pulmonary disease $\mathrm{n} \%$ & 811.8 & $1831.0 * *$ & 34.8 & $2021.5 * *$ \\
\hline Diabetes mellitus n \% & 1014.7 & 915.5 & 1422.6 & 3335.5 \\
\hline Arthritis n \% & 1826.5 & 1932.8 & 1829.0 & $5154.8 * *$ \\
\hline Stroke n \% & 45.9 & $1017.2 *$ & 46.5 & 99.7 \\
\hline Psychiatric disease $\mathrm{n} \%$ & 913.2 & 46.9 & 58.1 & 33.2 \\
\hline Hospitalization in past year n \% & 2536.8 & $3356.9 *$ & 1524.2 & $3739.8 *$ \\
\hline Activities of daily living. Mean (SD) & $87.4(22.0)$ & $66.9(30.1) * *$ & 88.7 (19.7) & $66.0(27.4) * *$ \\
\hline Geriatric depression scale. Mean (SD) & $3.2(2.1)$ & $5.8(3.1) * *$ & $3.7(2.8)$ & $5.9(3.4) * *$ \\
\hline Health-related quality of life (SF-12) & & & & \\
\hline
\end{tabular}


$* \mathrm{p} \leq 0.05$.

$* * \mathrm{p} \leq 0.001$

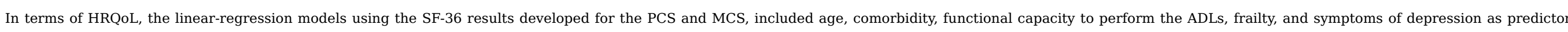

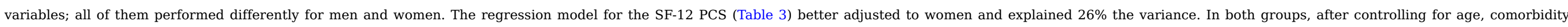

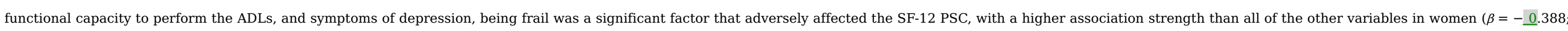

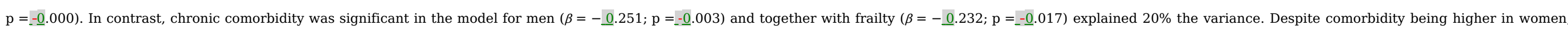

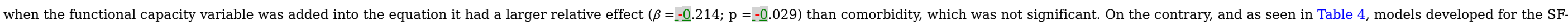
12 MCS showed that symptoms of depression were the only factor that could help to explain $22 \%$ of variance for both men $(\beta=-\underline{0} .492 ; \mathrm{p}=-\underline{0} .000)$ and women $(\beta=-\underline{0} .472 ; \mathrm{p}=-\underline{-0} .000)$.

Table 3 Multiple regression coefficients for physical component score of HRQL.

alt-text: Table 3

\begin{tabular}{|c|c|c|c|c|c|c|}
\hline \multirow[t]{2}{*}{ Variables } & \multicolumn{3}{|c|}{ Men } & \multicolumn{3}{|c|}{ Women } \\
\hline & $\beta$ & B (IC 95\%) & $\mathrm{p}$ value & $\beta$ & B (IC 95\%) & $\mathrm{p}$ value \\
\hline Age & -0.018 & $-0.019(-0.200-0.162)$ & 0.832 & 0.062 & $0.068(-0.087-0.22)$ & 0.387 \\
\hline Co-morbidities & -0.251 & $-1.87(-3.09-0.65)$ & 0.003 & -0.021 & $-0.153(-1.31-1.0)$ & 0.794 \\
\hline Activities of daily living & 0.133 & $0.039(-0.013-0.09)$ & 0.139 & 0.214 & $0.064(0.018-0.11)$ & 0.007 \\
\hline Geriatric depression scale & -0.079 & $-0.219(-0.72-0.28)$ & 0.392 & -0.044 & $-0.106(-0.457-0.245)$ & 0.552 \\
\hline Frailty & -0.232 & $-3.81(-6.94-0.68)$ & 0.017 & -0.388 & $-6.42(-9.21-3.63)$ & 0,000 \\
\hline $\mathrm{R}^{2}$ adjusted & 0.20 & & & 0,26 & & \\
\hline
\end{tabular}

Table 4 Multiple regression coefficients for mental component score of HRQoL.

alt-text: Table 4

\begin{tabular}{|c|c|c|c|c|c|c|}
\hline \multirow[t]{2}{*}{ Variables } & \multicolumn{3}{|c|}{ Men } & \multicolumn{3}{|c|}{ Women } \\
\hline & $\beta$ & B (IC 95\%) & $\mathrm{p}$ value & $\beta$ & B (IC 95\%) & $\mathrm{p}$ value \\
\hline Age & 0.014 & $-0,02(-0.249-0.296)$ & 0.865 & 0.012 & $0.023(-0.250-0.295)$ & 0.871 \\
\hline Co-morbidities & 0.016 & $0.182(-1.66-2.20)$ & 0.846 & -0.044 & $-0.546(-2.58-1.48)$ & 0.597 \\
\hline Activities of daily living & 0.055 & $0.025(-0.054-0.103)$ & 0.535 & 0.081 & $0.042(-0.040-0.12)$ & 0.316 \\
\hline Geriatric depression scale & -0.492 & $-2.09(-2.86-1.33)$ & 0.000 & -0.472 & $-1.93(-2.54-1.33)$ & 0.000 \\
\hline Frailty & 0.019 & $0.488(-4.23-5.21)$ & 0.838 & 0.046 & $1.29(3.61-6.20)$ & 0.603 \\
\hline $\mathrm{R}^{2}$ adjusted & 0.22 & & & 0.22 & & \\
\hline
\end{tabular}




\subsection{Discussion}

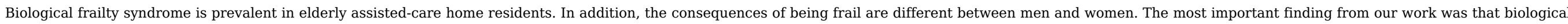
frailty syndrome plays a very relevant role in the physical dimension of the HRQoL and the impact of this in women is even higher than that produced by disability

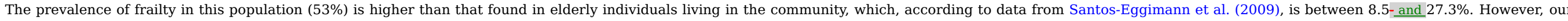

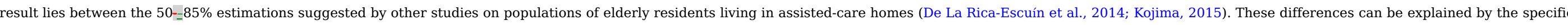
details of our population: old age, comorbidities, and disabilities, which are all factors related to frailty (Fried et al., 2001).

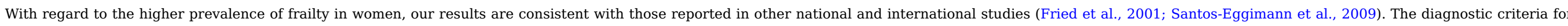

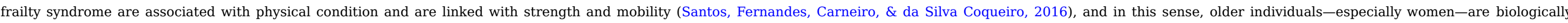

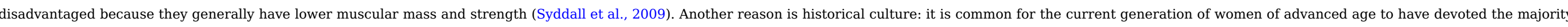

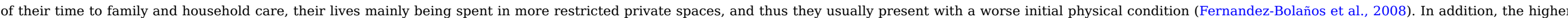

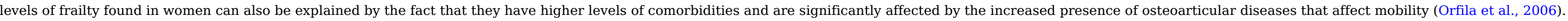

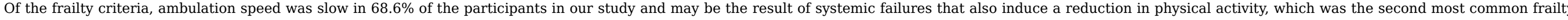

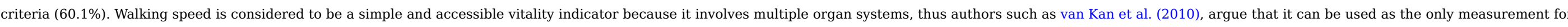

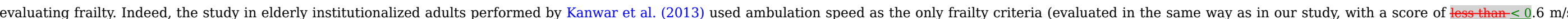
considered to be frail); they detected $66 \%$ frailty in their participants, which is consistent with our own findings.

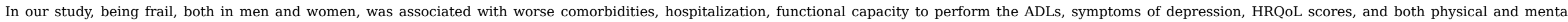

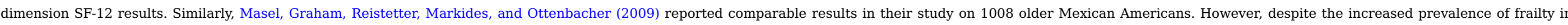

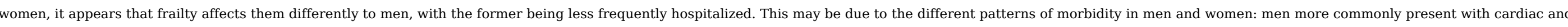
respiratory disease or ictus that later complicate, and generally require care that is more specialized.

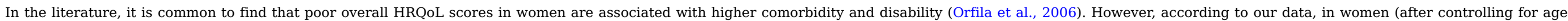

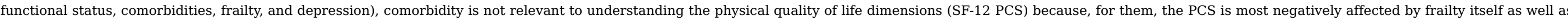

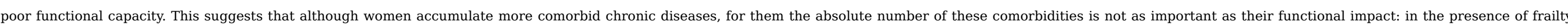
and disability, women tend to more negatively perceive their PCS.

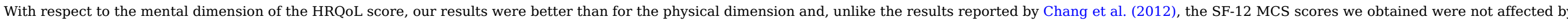

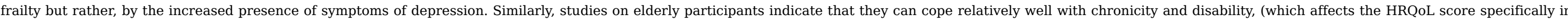
the SF-12 PCS but not the SF-12 MCS) and this can be improved if they feel that adequate psychosocial care resources are available to them (Bowling \& Iliffe, 2011)

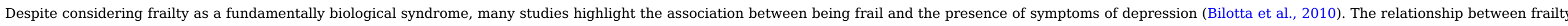

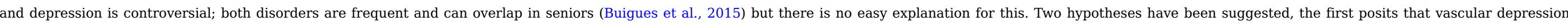

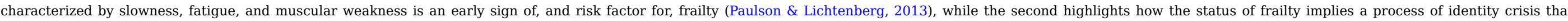

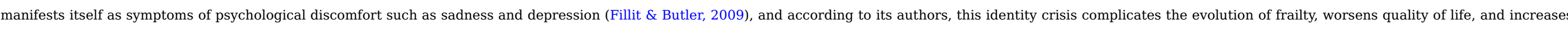

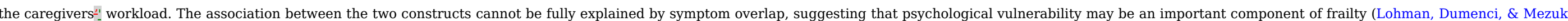
2015):

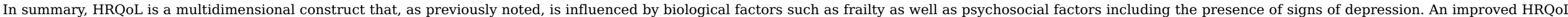
score implies that both aspects have been taken into account, resulting in the elderly person receiving comprehensive quality care. 


\section{5.}

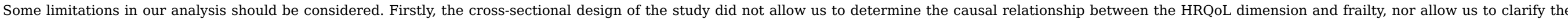

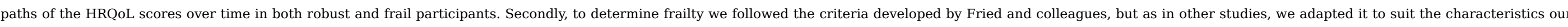

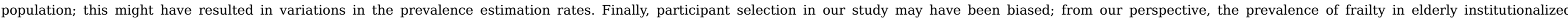

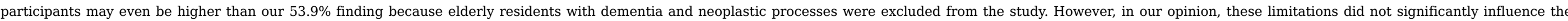

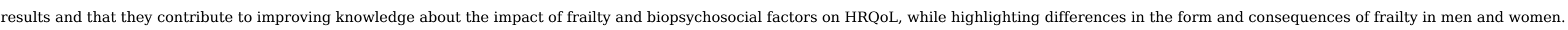

\section{6. $\underline{6}$ Clinical application and Econclusions}

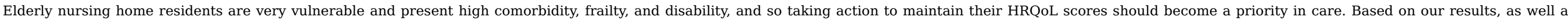

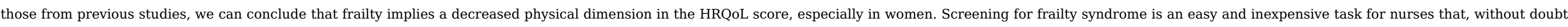

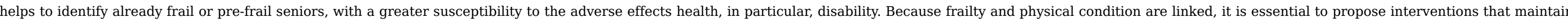

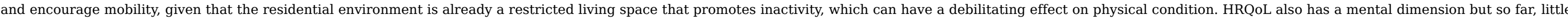

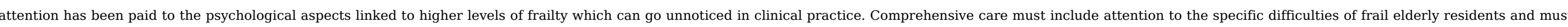
address the physical and emotional discomfort that accompanies these problems in an environment that favors neither activity nor the perception of control.

\section{Declaration of conflicting interests}

The authors declare that they have no potential conflicts of interest with respect to the research, authorship, and/or publication of this article

\section{References}

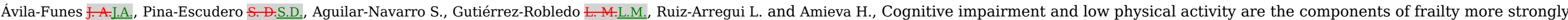
associated with disability, Journal of Nutrition, Health \& Aging 15 (8), 2011, 683-689, http://dx.doi.org/10.1007/s12603-011-0111-8.

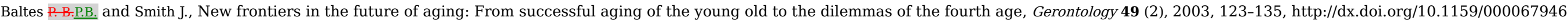

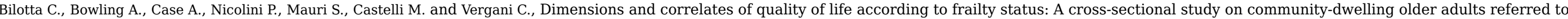
an outpatient geriatric service in Italy, Health and Quality of Life Outcomes 8, 2010, 56, http://dx.doi.org/10.1186/1477-7525-8-56

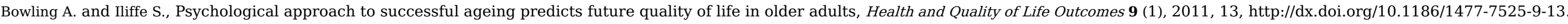

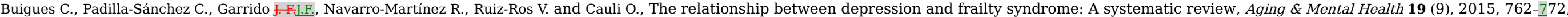

http://dx.doi.org/10.1080/13607863.2014.967174

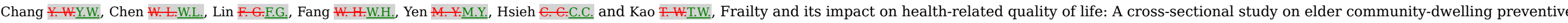
health service users, PloS One 7 (5), 2012, http://dx.doi.org/10.1371/journal.pone.0038079.

Clegg A., Young J., Iliffe S., Rikkert M. Q.M.O. and Rockwood K., Frailty in elderly people, The Lancet Vol. 381, 2013, 752-762, http://dx.doi.org/10.1016/S0140-6736(12)62167-9.

Cordeiro L. M.L.M., Paulino J.D. L.J.D.L., Bessa M. E. P.M.E.P., Borges E. L.C.L. and Leite S.F.P.S.F.P., Quality of life of frail and institutionalized elderly, ACTA Paulista de Enfermagem 28 (4), 2015, 361-366,

http://dx.doi.org/10.1590/1982-0194201500061.

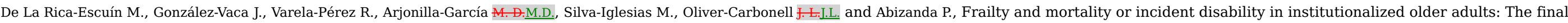
study, Maturitas 78 (4), 2014, 329-334, http://dx.doi.org/10.1016/j.maturitas.2014.05.022.

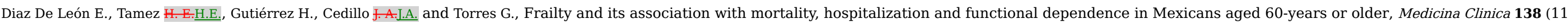




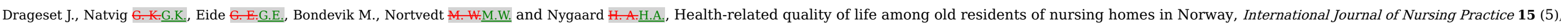
2009, 455-466, http://dx.doi.org/10.1111/j.1440-172X.2009.01794.x.

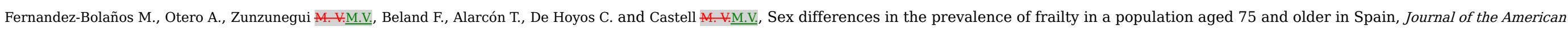
Geriatrics Society 56 (12), 2008, 2370-2371, http://dx.doi.org/10.1111/j.1532-5415.2008.02032.x.

Fillit H. and Butler R. N.R.N., The frailty identity crisis, Journal of the American Geriatrics Society 57 (2), 2009, 348-352, http://dx.doi.org/10.1111/j.1532-5415.2008.02104.x.

Folstein M. F.M.F., Folstein S.E.S.E. and McHugh P.R.P.R., Mini-mental state: A practical method for grading the state of patients for the clinician, Journal of Psychiatric Research 12, 1975, 189-198, http://dx.doi.org/10.1016/0022-3956(75)90026-6.

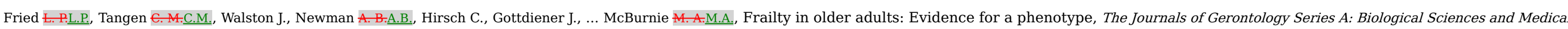
Sciences 56 (3), 2001, M146-M157, http://dx.doi.org/10.1093/gerona/56.3.M146.

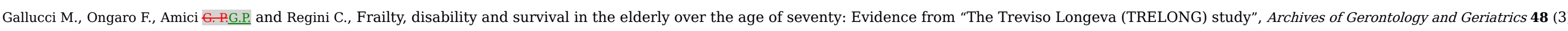
2009, 281-283, http://dx.doi.org/10.1016/j.archger.2008.02.005.

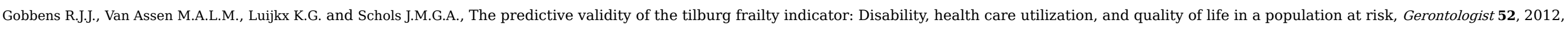
619-631, http://dx.doi.org/10.1093/geront/gnr135.

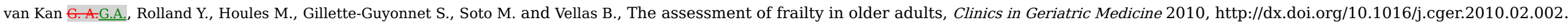

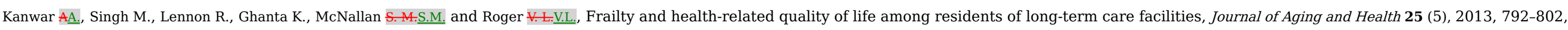
http://dx.doi.org/10.1177/0898264313493003.

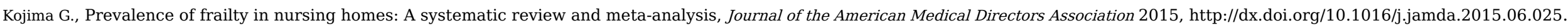

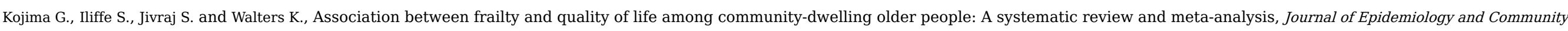
Health 2016, http://dx.doi.org/10.1136/jech-2015-206717, (jech-2015-206717).

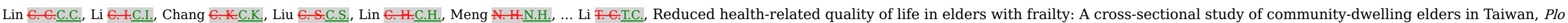
One 6 (7), 2011, 1-7, http://dx.doi.org/10.1371/journal.pone.0021841.

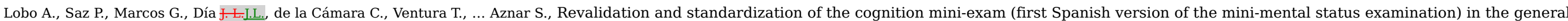
geriatric population, Medicina Clínica 112, 1999, 767-774.

Lohman M., Dumenci L. and Mezuk B., Depression and frailty in late life: Evidence for a common vulnerability, Journals of Gerontology, Series B: Psychological Sciences and Social Sciences 2015, http://dx.doi.org/10.1093/geronb/gbu180.

Mahoney F.I.F.I. and Barthel Đ. W.D.W., Functional evaluation: The barthel index, Maryland State Medical Journal 14, 1965, 61-65.

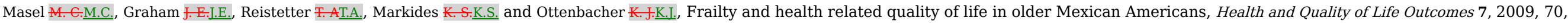
http://dx.doi.org/10.1186/1477-7525-7-70.

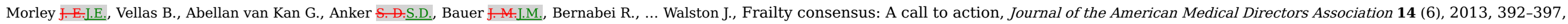
http://dx.doi.org/10.1016/j.jamda.2013.03.022. 


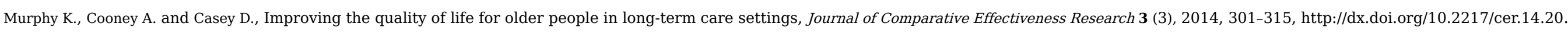

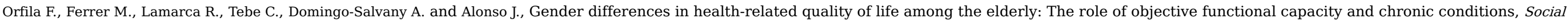
Science \& Medicine (1982) 63 (9), 2006, 2367-2338, http://dx.doi.org/10.1016/j.socscimed.2006.06.017.

Paulson D. and Lichtenberg P. a.P.a., Vascular depression: An early warning sign of frailty, Aging \& Mental Health 17 (1), 2013, 85-93, http://dx.doi.org/10.1080/13607863.2012.692767.

Rockwood K. and Mitnitski A., Frailty defined by deficit accumulation and geriatric medicine defined by frailty, Clinics in Geriatric Medicine 2011, http://dx.doi.org/10.1016/j.cger.2010.08.008.

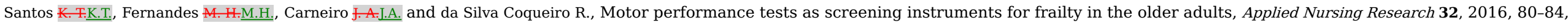

http://dx.doi.org/10.1016/j.apnr.2016.06.003.

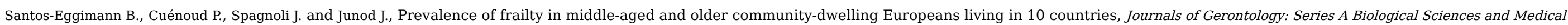
Sciences 64 (6), 2009, 675-681, http://dx.doi.org/10.1093/gerona/glp012.

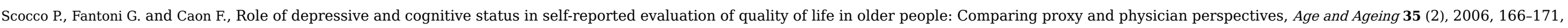
http://dx.doi.org/10.1093/ageing/afj026.

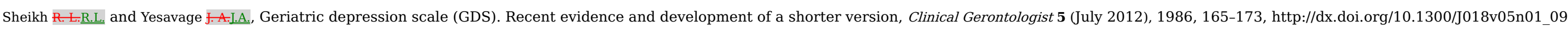

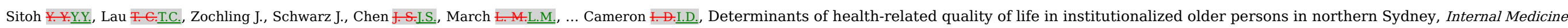
Journal 35 (2), 2005, 131-134, http://dx.doi.org/10.1111/j.1445-5994.2004.00742.x.

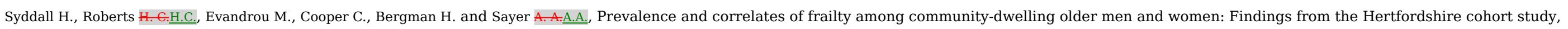
Age and Ageing 39 (2), 2009, 197-203, http://dx.doi.org/10.1093/ageing/afp204.

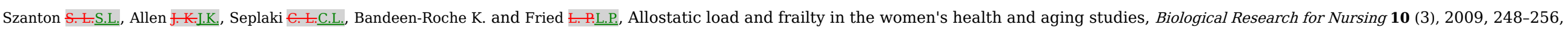

http://dx.doi.org/10.1177/1099800408323452.

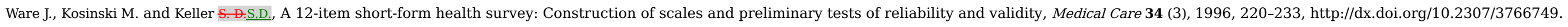

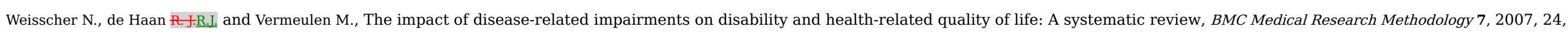

http://dx.doi.org/10.1186/1471-2288-7-24.

\section{Queries and Answers}

\section{Query:}

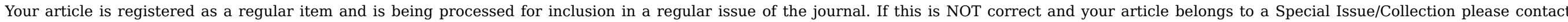
j.nocillado@elsevier.com immediately prior to returning your corrections.

Answer: Yes

Query:

Please check all author names if correct.

Answer: Yes

Query: 
The author names have been tagged as given names and surnames (surnames are highlighted in teal color). Please confirm if they have been identified correctly

Answer: Yes

Query:

Citation "Zaslavsky, Thompson, \& Demiris, 2012" has not been found in the reference list. Please supply full details for this reference.

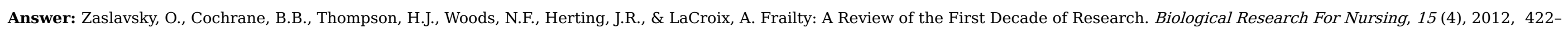
432. http://doi.org/10.1177/1099800412462866

Query:

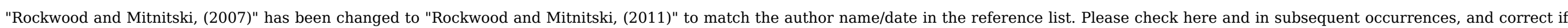
necessary.

Answer: OK, checked 